\title{
Exploring the factors influencing the negotiation process in cross-border M\&A
}

Article

Accepted Version

Creative Commons: Attribution-Noncommercial-No Derivative Works 4.0

Ahammad, M. F., Tarba, S. Y., Liu, Y., Glaister, K. W. and Cooper, C. L. (2016) Exploring the factors influencing the negotiation process in cross-border M\&A. International Business Review, 25 (2). pp. 445-457. ISSN 0969-5931 doi: https://doi.org/10.1016/j.ibusrev.2015.06.001 Available at https://centaur.reading.ac.uk/81841/

It is advisable to refer to the publisher's version if you intend to cite from the work. See Guidance on citing.

To link to this article DOI: http://dx.doi.org/10.1016/j.ibusrev.2015.06.001

Publisher: Elsevier

All outputs in CentAUR are protected by Intellectual Property Rights law, including copyright law. Copyright and IPR is retained by the creators or other copyright holders. Terms and conditions for use of this material are defined in the End User Agreement.

\section{www.reading.ac.uk/centaur}

\section{CentAUR}

Central Archive at the University of Reading 
Reading's research outputs online 


\title{
Exploring the Factors Influencing the Negotiation Process in Cross-Border M\&A
}

\author{
Mohammad Faisal Ahammad ${ }^{a}$, Shlomo Y. Tarbab, Yipeng Liu ${ }^{\text {b,c }}$, Keith W. Glaister ${ }^{\text {, }}$, Cary L. \\ Cooper $^{\mathrm{e}}$
}

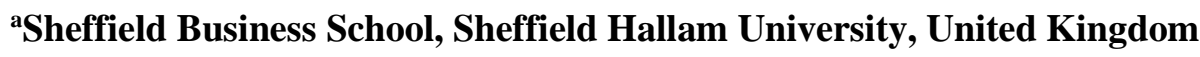

${ }^{b}$ Birmingham Business School, University of Birmingham, United Kingdom

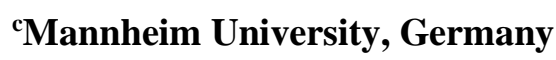

${ }^{\text {d} W a r w i c k ~ B u s i n e s s ~ S c h o o l, ~ U n i v e r s i t y ~ o f ~ W a r w i c k, ~ U n i t e d ~ K i n g d o m ~}$

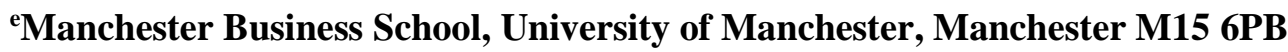




\begin{abstract}
This research study provides an empirical examination of the impact of national cultural distance, organizational cultural differences, communication, and planned employee retention on the effectiveness of negotiation process in the cross- border Mergers \& Acquisitions (M\&As). We developed and tested a conceptual framework of negotiation process in order to provide a framework to analyze the key components of the negotiation process of the cross border M\&A. The findings indicate that communication positively influence antecedent and concurrent phase of negotiation process. In addition, national cultural distance and organisational cultural differences negatively influence the effectiveness of concurrent phase. We also found that national cultural distance moderates the relationship between communication and effectiveness of concurrent phase of the negotiation process, as such that the positive effect of communication is lower when national cultural distance is higher. We also found that planned employee retention positively affect the effectiveness of concurrent phase. Finally, the effectiveness of concurrent phase positively influence the effectiveness of consequent phase i.e. M\&A agreement. The contribution of this study lies in providing new insights on negotiation-associated factors for incumbent executives, in order to enable them to better plan and implement cross-border mergers and acquisition deals.
\end{abstract}

Keywords: Negotiations, cross-border mergers and acquisitions, national cultural distance, organizational cultural differences, communication, planned employee retention. 


\section{INTRODUCTION}

The frequency and scale of mergers and acquisitions (M\&A) have significantly increased during the past two decades in spite of continuous reports on their high failure rates (e.g., Cartwright \& Cooper, 1996; 2000; Reus, \& Lamont, 2009; Weber, Tarba, \& Oberg, 2014). Unfortunately, studies from different scientific streams have generally failed to develop synergistically, hence missing the opportunities from cross-fertilization (Weber, Tarba, \& Reichel, 2009). Recent reviews (e.g., Schweiger, \& Goolet, 2000; 2005; Stahl, \& Voigt, 2008; Weber, Tarba, \& Reichel, 2011) point out that most of the existing research on the human side of M\&As has been a-theoretical, fragmented across various disciplines, has not been systematic and linked to any comprehensive theory, and rarely have models been proposed that were applicable across different organizations.

The degree of organizational change, following various post-acquisition integration approaches, may vary substantially across different national and cultural settings. Thus, the impact of M\&A on individuals and groups may differ widely between various human resource management practices (Budhwar, Varma, Katou, \& Narayan, 2009; Weber, \& Tarba, 2010), evoked cultural change following acculturation between combining firms (Kavanagh, \& Ashkanasy, 2004), leadership approaches in M\&A (Kavanagh, \& Ashkanasy, 2006), individual psychological and emotional reactions to the organizational change in general and M\&A in particular (Kiefer, 2002; 2005; Kusstatscher, \& Cooper, 2005; Kusstatscher, 2006; Sinkovics, Zagelmeyer, and Kusstatscher, 2010), coping strategies with M\&A (Amiot, Terry, Jimmieson, \& Callan, 2006; Scheck, \& Kinicki, 2000), and selfattribution biases in M\&A (Billett, \& Qian, 2008). Yet, rather strikingly the topic of negotiation, and associated with it cultural challenges in the specific context of cross-border M\&A, is still rather underexplored (Weber, Belkin, \& Tarba, 2011). 
Albeit post-merger M\&A performance of acquiring firms is disappointing, cross-border M\&A is a sought-after corporate strategy (Cartwright \& Schoenberg, 2006). There might be some unidentified moderating variables which affect M\&A performance (Stahl \& Voigt, 2008). Scholars argue that a successful M\&A is strongly correlated with early and ongoing cooperative negotiations, until the deal is actually signed (Saorín-Iborra, 2006; 2008; Sebenius, 1998). In addition, many M\&A failures can be partially attributed to lack of fruitful contacts and information exchange between acquiring and target firms at various stages (de Beaufort \& Lempereur, 2003). Therefore, an understanding of the factor influencing effective negotiation process is vital for the success of cross border M\&A.

As noted by Ghauri \& Usiner (2003) and Graham, Mintu, \& Rodgers (1994) "negotiation" is viewed as an ongoing process consisting of three phases: antecedent, concurrent and consequent. The antecedent part relates to the pre-interaction phase, the preparation and the information gathering. In the particular context of cross-border M\&A, acquiring firm needs to collect information regarding the target firm before it starts negotiations with it. The concurrent phase is the process of negotiation per se entailing the interaction between the incumbent parties (Graham, 1985a). Furthermore, as maintained by Greenhalgh, Neslin, \& Gilkey (1985) the behaviors and processes during the concurrent stage act as mediators of the outcomes at the consequent phase. In the context of cross-border M\&A, the afore-mentioned consequent phase refers to reaching an actual agreement to close an M\&A deal. Therefore, in our view, the process perspective on negotiation may advance largely our comprehension of cross-border M\&A endeavours.

The aim of the paper is to investigate the factors influencing the effectiveness of negotiation process in cross border acquisitions. Specifically, the paper examines the impact of cultures, communication and planned employee retention on the effectiveness of negotiation process in the context of cross border acquisitions. 
Our paper is organized as follows. First, we provide an exhaustive review of the literature on the negotiations in general and then in the specific context of M\&A. Afterwards we present the hypotheses development, methodology used, and the results. In the following section we discuss the findings and finally present the conclusions and managerial implications.

\section{Literature Review and Hypotheses Development}

Negotiation has been investigated mainly from social psychological and behavioral decision perspectives (Bazerman, Curhan, Moore, \& Valley, 2000; Ghauri, 2003; Thompson, Wang, \& Gunia, 2010). International business negotiations received increasing attention as a full part of the managerial process, highly relevant to the implementation of international business strategies ranging from macro-strategic perspective on organizations to microbehavioral perspectives on individuals (Ghauri \& Usunier, 2003; Weiss, 2006). From the negotiation process perspective, Ghauri (2003) structures the international business negotiation process in terms of the pre-negotiation, negotiation, and post-negotiation stages. These stages are influenced by factors, such as culture, strategy, background, and atmosphere.

As a metaphor, inter-cultural negotiation process resembles a dance, where one person does a waltz with another doing a tango (Adair \& Brett, 2005). Viewing a kind of 'dilemma of differences', the different cultural scripts present procedural conflict at the bargaining table, while differences in preferences present opportunities for both parties (Tinsley, 2001; Tinsley, Curhan, \& Kwak, 1999). Multiple models of negotiation exist (Lewicki, Weiss, \& Lewin, 1992), such as the parties' relationship and parties' behaviors (Weiss, 1993), the stages view of negotiation (Graham, 1985b), cultural influences (Gelfand \& Brett, 2004), self regulation (Brett, Northcraft, \& Pinkley, 1999) and dynamics of relational self (Gelfand, Major, Raver, Nishii, \& O'BRIEN, 2006). There is increasing literature on culture and 
negotiation, however, the influence of culture on negotiation tactics and outcomes awaits further scholarly inquiry (Gelfand \& Dyer, 2000). Culture is a major determinant of strategies and tactics in international business negotiation, because negotiations involve communication, time, and power and these variables vary across different cultures (Ghauri \& Usunier, 2003). We believe cross-border merger and acquisition (M\&A) can offer the ideal empirical setting to advance our understanding by investigating the negotiation process.

In this section, we will review the literature streams of cultural differences, communication and planned employee retention in cross-border M\&A negotiation, developing our hypothetical constructs accordingly. Culture can influence the process of business negotiations (Graham, 1985b), and business negotiations vary across cultural groups (Graham et al., 1994) . In today's globalized and interdependent world, understanding culture and cross-cultural issues is central to understand negotiation (Gelfand \& Brett, 2004). Two functions of negotiations exist, namely, "value creation" via integrative negotiation (win-win) and "value claiming" via distributive negotiation (win-lose) (Thompson et al., 2010). In the context of cross-border M\&A, value creation via integrative negotiation is supposed to be what acquiring and target firms aim to achieve.

\section{The process perspective of negotiation in cross border acquisitions}

\section{Communication}

Communication is of critical importance in affecting negotiation process. It is urged to take a contextual view of communication in order to understand negotiation process, whereas different situational conditions can affect the patterns of frequencies, sequences, and phases of negotiation communication (Weingart \& Olekalns, 2004). Despite similarities between the negotiating parties in national culture and language, the merger negotiation between two 
large telecom operators the Swedish Telia and the Norwegian Telenor, eventually failed largely due to communication strategies (Fang, Fridh, \& Schultzberg, 2004; Meyer \& Altenborg, 2008). The medium choice of communication affects the negotiation process and outcomes (Valley, Moag, \& Bazerman, 1998). Face-to-face communication enabled participants to foster greater rapport and cooperation than audio-only communication (Drolet \& Morris, 2000). However, when arousal is high, audio-only communication may reduce the likelihood of pressure tactics (Lewis \& Fry, 1977). The technological advancement and availability of communication channels, such as telephone, fax, email, etc., can affect the negotiation process. Moreover, media accounts of acquisition can promote international relations, which may affect international acquisitions (Riad, Vaara, \& Zhang, 2012).

"Communication" is regarded as the most important ingredient for post-acquisition integration. Contact between employees of the two companies is needed for managerial and cultural integration (Shrivastava, 1986), and the creation of communication channels can facilitate the coordination and knowledge flows between firms (Chesbrough \& Teece, 2002). The release of preview of merger announcement reduced dysfunctional outcomes of a merger in comparison to the employees who received limited information (Schweiger \& Denisi, 1991). Interestingly, Saorín-Iborra (2008) reached the conclusion that the time pressure perceived by negotiation parties during acquisition negotiations impacts the communication between them (Saorín-Iborra, 2008). Another recent study using interaction data from employee communication logs found out the communication patterns across firms develop slowly, and communication routines persist even in an acquisition event (Allatta \& Singh, 2011). In our current study, the intended integration approach is "absorption acquisition", where there is a relatively high need for interdependence between the firms to transfer capabilities and low need for autonomy between firms to preserve the boundaries (Haspeslagh \& Jemison, 1991). Even in such an active high-level integration mode, the 
communication patterns are slow to change. A clear communication strategy, aligned with the integration strategy and the desired culture of the new organization, is a critical component of a successful integration strategy (Gomes, Weber, Brown, \& Tarba, 2011b). We argue that clear and frequent communication involving key stakeholders in the negotiation process will enable the acquiring and target firms to better understand various expectations and integration strategy after the transactions. This communication strategy can smooth the integrative negotiation process in cross-border M\&A.

According to Datta \& Yu (1991) the better informed the acquiring firm is of the target firm, the better are the odds of attaining the greatest benefits from the negotiation process. Coff (1999) found that the lengthening of negotiation process in knowledge-intensive industries leads slower momentum thus allowing the negotiating parties to better share information without time pressures. In the same vein, Weber, Tarba, \& Oberg (2014) note that information exchange between amalgamating entities can reduce the level of ambiguity thus improving the chances of negotiations and also the overall M\&A deal success.

We thus hypothesize:

H1: Communication between acquiring firm and target firm will positively influence the antecedent phase of negotiation process

H2: Communication between acquiring firm and target firm will positively influence the concurrent phase of negotiation process

\section{National cultural differences}

Hofstede's $(1980 ; 2001)$ cultural differences and cultural values framework witnessed a vast variety of empirical studies in business and psychology journals (Kirkman, Lowe, \& Gibson, 2006). Scholars argue that cultural institutions provide contexts for negotiations, while 
culture provides scripts and schemas for negotiation (Leung, 1997). Cross-cultural research comparing negotiations in different cultures suggests the distinctive negotiating styles (Graham, 1993; Graham \& Lam, 2003; Graham et al., 1994; Sebenius \& Qian, 2008). In the realm of international negotiations, studies stated that cultural differences, such as individualism versus collectivism, affect negotiation process (Gelfand \& Realo, 1999), judgment biases in negotiation (Gelfand et al., 2002), negotiation behavior (Adair, Okumura, \& Brett, 2001), conflict resolution strategies (Tse, Francis, \& Walls, 1994), and negotiation joint gains (Brett \& Okumura, 1998). Tension felt in international business negotiations affect trust of negotiators' counterparts (Lee, Yang, \& Graham, 2006). A recent 33-nation study reveals the differences between tight and loose cultures (Gelfand et al., 2011). In their view, tight cultures have many strong norms and a low tolerance of deviant behavior, whereas loose cultures have weak social norms and a high tolerance of deviant behavior. They suggested an integrated multilevel system which incorporates both historical factors and contemporary processes to understand the national cultural differences.

Negotiations in the context of cross-border M\&A require the acquiring firms not only to attend the local traditions and etiquette, but understand the deeper and subtle governance and decision-making processes shaped by national cultures (Sebenius, 2002a, b). A case study on SMI, an Italian copper-products firm, which navigated through and negotiated successful cross-border M\&As in France and Germany, illustrates the benefits of understanding national cultural differences (Sebenius, 1998). An explorative study on M\&A cross European borders found out that national culture differences play an important role in affecting acquirer's perceptions of target companies, which have important consequences for the negotiation of deals (Angwin, 2001). One exemplary study from a socio-cultural perspective developed a business negotiation process model based on Swedish multinational Ericsson and its negotiation process for various projects in China (Ghauri \& Fang, 2001). 
In the research of international alliances, cultural distance were found to affect negotiators' tactics (Rao \& Schmidt, 1998). One study shows the judgment bias in which negotiators fail to accurately understand their counterparts' interests, would be more prevalent at the end of negotiations in an individualistic culture than collectivistic culture (Gelfand \& Christakopoulou, 1999). Cultural values and norms are evident in a negotiator's implicit theory about negotiation that guide what strategies are available to negotiators (Adair \& Brett, 2005). In the context of cross-border M\&A, national culture differences can place hurdles for M\&A partners to prepare and enter the negotiation process.

We thus hypothesize:

H3: National cultural difference will negatively influence the concurrent phase of negotiation process

\section{Organizational cultural differences}

Scholars argues that organizations or institutions may serve as barriers to negotiations (WadeBenzoni et al., 2002). The relationships between organizational cultural differences and other human factors to the effectiveness of the integration process are complex and vary across different industry sectors (Weber, 1996; Weber, Shenkar, \& Raveh, 1996). Recent quantitative research advanced our understandings on the influences of national and organizational culture differences, and culture integration mechanisms, on actual post M\&A integration processes (Sarala, 2010; Sarala \& Vaara, 2010). Beyond for-profit M\&A setting, organizational culture also plays a significant role in the outcomes of the merger integration process nonprofit M\&A (La Piana, \& Hayes, 2005). It is recommended that the negotiations committee assess the culture of each organization and understand the existing differences (La Piana \& Hayes, 2005). A recent study empirically tested the effects of organizational cultural preservation, multiculturalism, and partner attractiveness on post-acquisition conflicts (Sarala, 2010). The results indicate that organizational cultural differences and organizational 
cultural preservation increase conflicts. Amid the increase of conflicts, we argue that organizational cultural differences may negatively affect the negotiation process. In the context of international joint venture, organizational antecedents affect negotiation process and variables, such as term specificity and topic inclusiveness (Luo, 1999; Luo \& Shenkar, 2002).

In cross-border $M \& A$, the corporate agents need to develop early strategies to obtain relevant information from the other side, while sharing information with prospective partners, so as to increase the chance of common understandings. This requires the acquiring company actively listen to target's concerns and constraints, then to develop a persuasive argument and build a compelling case. However, such cooperation cannot be simply taking place between two different organizational cultures.

We thus hypothesize:

H4: Organizational cultural difference will negatively influence the concurrent phase of negotiation process

\section{Planned employee retention}

Post-acquisition integration plays important role in achieving synergy after M\&A transactions (Gomes, Weber, Brown, \& Tarba, 2011a; Weber, Tarba, \& Bachar, 2011b). Organizational integration, such as interaction and coordination between the two firms involved in the acquisition, is considered as the most influential factors for achieving synergies (Larsson \& Finkelstein, 1999; Larsson \& Lubatkin, 2001). Although human resources (HR) practices, such as training, communication and autonomy are important to M\&A performance, there is no clear best practice to address the cross-cultural conflict situations with cross-border M\&A (Weber, Rachman-Moore, \& Tarba, 2011a; Weber \& Tarba, 2010). Weber \& Tarba (2010) suggest that acquirers must use HR practices to develop integration capabilities during post-merger integration to enhance M\&A performance. 
Based on a model that encompasses national culture dimensions, corporate culture differences, and the synergy potential between the merging firms Gomes, Weber, Brown, \& Tarba (2011) and Weber, Tarba, \& Reichel $(2009 ; 2011)$ proposed that the reason for the dismal performance track record of the acquiring companies is likely to lie in inability or failure to adopt and/or implement the integration approach necessitated in each specific case. In this context, Tarba (2009) based on a large sample data about M\&A deals in the Israeli high-tech industry between 1990 and 2006, found that there is a significant difference in the extent of the fit between the integration approaches that should be and that were actually applied by the acquirers based on the model of Haspeslagh \& Jemison (1991). Specifically, only $42 \%$ of M\&A transactions in the sample actually have showed an afore-mentioned fit (Tarba, 2009). Another recent study's findings suggested that post-acquisition integration approach plays a mediating role in the relationships between both synergy potential and organizational culture, and subsequent integration effectiveness (Weber et al., 2011b).

The creation of a trust relationship during the negotiation process is considered essential, and post-negotiation atmosphere is important for the post integration phase and performance. When the value of the acquisition is generated by leveraging the knowledge target firms' human capital, it is crucial to avoid the turnover of key staff (Ranft \& Lord, 2002). Although previous studies suggest the M\&A negotiation impacts target company top management turnover (Hambrick \& Cannella Jr, 1993; Walsh, 1989), there is scant research on the influence of planned employee retention on negotiation process. An employee retention plan may lower CEO resistance to takeover (Buchholtz \& Ribbens, 1994). Human beliefs and professional attitudes such as the fear of change and the insecurity during the negotiations affect the result of merger (Konstantopoulos, Sakas, \& Triantafyllopoulos, 2009). One study on joint venture negotiation found out that satisfaction with the relationship created between partners is the most suitable indicator of negotiation outcome (Saorín-lborra, 2006). The role 
of affect in cross-cultural negotiations influences the character of the negotiation process (George, Jones, \& Gonzalez, 1998). Emotion can shape the dynamics of intercultural negotiation process (Kumar, 2004). The planned employee retention plan might resonate with positive affect and emotion which in turn influences the cross-border M\&A negotiation process. Thus, the planned employee retention and potential job creations can be perceived positively by the target firms which may enhance the effectiveness of concurrent phase of negotiation process.

We thus hypothesize:

H5: Planned employee retention will positively influence the concurrent phase of negotiation process.

\section{Moderating effect of culture on communication and negotiation process}

National culture distance affects the extent to which acquisition partners communicate during negotiation process and integration process. Several studies report that national culture has an important influence on how people interact with others. For example, Hofstede (2001) explained that in cultures that are characterised by large power distance, centralisation of communication is popular, whereas in small power distance cultures decentralisation is popular. Research on cross-cultural communication found that mothers from collectivistic cultures tend to encourage listening and empathy in their children, whereas mothers from individualistic cultures tend to teach self-expression (Singelis and Brown, 1995). These differences are likely to lead to very distinct communication styles and expectations from communication.

During the concurrent phase, acquiring and target firm can convey critical information about the target firm's capabilities and provide, or ask for, clarification and explanation about these capabilities. Moreover, communication functions as an important driver of trust between 
groups (Citera and Rentsch, 1999). However, culture distance makes it more difficult for employees to interact and share ideas, and, as a result, impedes communication. Even when language differences are not present, or are overcome through training and education, organisation members are likely to prefer, and have greater opportunities for, communicating with other members from similar cultures rather than with members from distant cultures (Lane et al., 2004). Therefore, during the concurrent phase of a negotiation process, the positive effect of communication on concurrent phase is lower when the national cultural distance between the acquiring and target firm is very high. Based on the above argument, we propose the following hypothesis:

H6: National cultural distance negatively moderates the relationship between communication and concurrent phase of a negotiation process. Specifically, the positive effect of communication is lowest when the national cultural distance between acquiring and target firm is very high.

Organizational culture influences the integration approach of cross-border M\&A (Weber, Tarba, \& Reichel, 2011c; Weber, Teerikangas, Rouzies, \& Tarba, 2011d). The cross-border acquisitions by Teva Pharmaceuticals illustrate the organizational cultural differences lead to different communication strategies (Almor, Tarba, \& Benjamini, 2009; Tarba, Almor, \& Benyamini, 2011). One recent study contrasting state-owned enterprises and privately-owned enterprises of Chinese firms' cross-border acquisitions in Europe manifests the variations of communication approaches, which may lead to different negotiation tactics and outcomes (Liu \& Woywode, 2011). The flexible and open organizational culture tends to convey M\&A motives and integration strategy explicitly to the target firms. However, the moderating effect of organizational cultural differences on concurrent phase of a negotiation process should be considered with caution. Irrelevant information sharing among negotiation partners may have 
a detrimental effect, where too much information can impair negotiators' effectiveness (Wiltermuth \& Neale, 2011). It is not necessary that the more information sharing among partners, the better the cross-border M\&A negotiation process is. Furthermore, straightforwardness can become a liability in negotiation due to integrative potential and structural power (DeRue, Conlon, Moon, \& Willaby, 2009). Accordingly, the positive effect of communication on concurrent phase is lowest when the organisational cultural difference is very high.

H7: Organizational cultural differences negatively moderate the relationship between communication and concurrent phase of a negotiation process. Specifically, the positive effect of communication is lowest when the organisational cultural differences between acquiring and target firm is very high.

\section{The relationship between different phases of negotiation process}

"Negotiation" is viewed as an ongoing process consisting of three phases: antecedent, concurrent and consequent (Graham et al., 1994). The antecedent part refers to the preinteraction phase, the preparation and the information gathering. In the context of cross border M\&A, acquiring firm needs to gather information about the target firm such as profitability, management styles before commencing the negotiation with the target firm. The concurrent phase is the process of negotiation per se. It is the interaction between the parties, where negotiating behaviours come into play (Graham, 1985a); they act as mediators of the outcomes following in the consequent phase (Greenhalgh, Neslin, \& Gilkey, 1985). In the context of cross border M\&A, managers involved in M\&A negotiation can feel pressure to conclude the deal or managers could have multiple motives for the M\&A deal which could impair effective negotiation. This consequent phase refers to the outcomes of the negotiation (Paik \& Tung, 1999). They are generally considered as distributive (win-lose) or integrative 
(win-win). In the context of cross-border M\&A, the consequent phase is an agreement of a cross-border M\&A deal. Therefore, in our view, the process perspective on negotiation may advance largely our understanding of cross-border M\&A endeavours.

During the antecedent phase, acquiring firm has the opportunity to understand the differences in culture and management styles (Schweiger \& Very, 2001) and better prepare for the next stage, the concurrent phase. The failure to plan the negotiation process can negatively impact the consequent M\&A deal performance (Weber, Belkin, \& Tarba, 2011). For instance, an ineffective preparation in the antecedent phase may lead to unexpected conflicts and arguments during the concurrent phase, while an effective management of the antecedent phase is expected to have a positive influence on the concurrent phase.

Moreover, an effective concurrent phase is likely to impact the consequent phase i.e. outcome of the negotiation. During the concurrent phase, the acquiring firm feels the pressure of concluding the deal and attempt to effectively negotiate the terms and condition of the acquisitions such as a suitable employment contract with the foreign target firm. An ineffective concurrent phase may lead to the break-down of the negotiation or lead to disagreement between the acquiring firm and foreign target firm. Therefore, an effective concurrent phase is expected to have a positive influence on the consequent phase i.e. the outcome of cross border M\&A negotiation. Based on the above arguments, we propose the following hypotheses:

H8: Antecedent phase positively influence the concurrent phase

H9: Concurrent phase positively influence the consequent phase i.e. M\&A agreement

In Figure 1, we draw the relationships of the nine hypotheses derived from literature review.

---Please insert Figure1 about here--- 


\section{METHODOLOGY}

\section{Data collection:}

We conducted a cross-section survey involving data collection through a self-administered questionnaire in 2007. In this study, we look into cross border acquisition transactions undertaken by UK firms, with a period of five years (2000-2004). At first, we gathered the M\&A cases from Thomson One Banker Database. The sample includes those M\&A deals in which the acquirer bought a 100 percent equity stake in the acquired company. Based on the results of the website search and telephone enquiries, a list key informants and potential survey participants was assembled. After eliminating companies with a policy of nonparticipation in surveys, we obtained a final sampling frame of 591 international acquirers.

591 questionnaires were sent to potential survey participants (i.e., UK acquiring firm managers). We made an effort to recognize the managers involved in acquisition decision and implementation process. In order to encourage for accurate responses, the respondents were guaranteed anonymity and were promised a summary report of research findings if requested. After three reminders, we received 65 completed and usable questionnaires, representing a response rate of $11 \%$. This response rate is comparable with the ones found in the surveys involving executives (Graham and Harvey, 2001; Colombo, Conca, Buongiorno and Gnan, 2007; Mukherjee, Kiymaz and Baker, 2004). This response rate is a reasonable one given the senior positions of the respondents and the sensitivity of the information, the welldocumented difficulties of obtaining questionnaire responses from executives (Harzing, 1997), and the decreasing rate of response from executives (Cycyota and Harrison, 2006).

All of the respondents had been directly involved in managing the CBA process. An examination of the job titles revealed 23 Business Development Directors, 16 Finance Directors or Chief Financial Officers, 12 Chief Executive Officers, 8 Managing Directors, 6 Executive Directors. The sample represents acquisition activity on two continents: North 
America and Europe. Europe is represented by 35 acquisitions. In North America, the acquired firms are from the USA and Canada (21 and 9 respectively).

\section{Common method bias:}

When a survey method is used to collect data using a single source, common method bias is a potential issue. Since the dependent variables (e.g. concurrent phase), some of the independent variables (e.g. organizational cultural differences, planned employee retention), and the control variables (e.g. past performance of target firm) are based on data provided by a single individual, they may be affected by common method bias. This is unlikely, however, because the items measuring these variables are measured through a large number of items and are dissimilar in content. Moreover, in order to minimize the problem of common method bias, a combination of subjective measures (e.g. organizational cultural differences) and objective measures (e.g. national cultural distance, consequent phase) has been used to measure the key variables. We also guaranteed anonymity to all respondents and urged them to respond to questions as honestly as possible considering that there were no right or wrong answer and results would only be presented to third parties in aggregate form. In addition, we checked for common method bias by conducting Harman's single-factor test. A substantial amount of common method bias exists when a single factor emerges or one general factor accounts for over $50 \%$ of the variance (Podsakoff, et al., 2003). When independent and dependent variables of this study were included, the un-rotated factor analysis produced 4 factors. The largest factor explained $20.16 \%$ of the total variance. Based on Harman's test we can conclude that there was no serious common method variance present in our data. Finally, the presence of complex relationships, such as interaction, among dependent and independent variables that are unlikely to be part of the individual rater's cognitive map reduce the chances for common method variance effects (Chang et al., 2010).

\section{Retrospective Bias:}


Respondents need to recollect information about the past events in a survey research. Potentially this exposed the study to retrospective bias, because some information may be lost or distorted over time. We adopted a research design and survey instrument anticipated to minimise retrospective bias. In addition, in order to assess potential retrospective bias, responses concerning acquisitions made in 2004 were compared to acquisitions made in 2000. The t-tests for mean differences in variables were calculated, and no statistically significant differences were found in means between responses concerning acquisitions made in 2000 compared to acquisitions made in 2004. The findings are reported in Table 1.These findings suggest that retrospective bias does not pose a problem for the study.

----Please insert Table 1 about here----

\section{Non-response bias:}

We evaluated non-response bias by using two procedures (following Ranft and Lord, 2000). First, we compared early with late respondents along a number of key descriptive variables. The findings are reported in Table 2. Differences between the two groups were not statistically significant, suggesting that non-response bias is not evident.

----Please insert Table 2 about here----

Second, the possibility of non-response bias was checked by comparing respondent and nonrespondent firms in terms of the transaction value and total sales. The average transaction value of cross border acquisitions included in the sample was $£ 251$ million, which is not significantly different from the average transaction value ( $£ 218$ million) for acquisitions of non-participating firms $(\mathrm{t}=0.406, \mathrm{p}=0.685)$. The $\mathrm{t}$-tests of mean difference were 
insignificant, confirming no systematic bias between the responding firms and nonresponding firms.

\section{Operationalization of the constructs:}

\section{Dependent variables - Effectiveness of negotiation process}

Based on the theoretical framework of Graham et al. (1994), we developed questionnaire related with three phases (i.e. antecedent, concurrent and consequent) of negotiation process. The antecedent phase refers to the pre-interaction phase, the preparation and the information gathering. In the context of cross border M\&A, acquiring firm needs to gather information about the target firm such as profitability, management styles before commencing the negotiation with the target firm. The effectiveness of Antecedent phase depends on the effective management of pre-interaction phase by ensuring reliability of information collected and by ensuring that acquiring firm understand the differences in culture and management styles between foreign target firm and UK acquiring firm. Through a review of previous research on acquisition (e.g. Very and Schweiger, 2001), three Antecedent phase issues were identified: 1) ensuring reliability of information collected, 2) understanding different cultures, and 3) understanding different management styles. Respondents were asked to indicate the extent to which acquired firm were able to effectively manage the above issues in a 5-point likert scale, anchored from 1 (= 'Less effective') to 5 (= 'Highly effective'). These 3 items are measuring "the effectiveness of Antecedent phase".

The Concurrent phase is the process of negotiation per se. It is the interaction between the parties, where negotiating behaviours come into play (Graham, 1985a); they act as mediators of the outcomes following in the consequent phase (Greenhalgh, Neslin, \& Gilkey, 1985). In the context of cross border M\&A, managers involved in M\&A negotiation can feel pressure to conclude the deal or managers could have multiple motives for the M\&A deal which could 
impair effective negotiation. The effectiveness of Concurrent phase depends on how the acquiring firm manages the pressure during the negotiation and how acquiring firm effectively negotiate the terms and condition of the acquisitions such as a suitable employment contract with the foreign target firm. Three Concurrent phase issues were identified from existing literature (two issues from Haspeslagh and Jemison 1991; one issue from Very and Schweiger, 2001: 1) increased personal pressure to conclude the deal, 2) Multiple motives of employees (from acquiring and acquired firm) involved in the negotiation process could lead to negotiation problems, and 3) negotiating employment contract. Respondents were asked to indicate the extent to which acquired firm were able to effectively manage the above issues in a 5-point likert scale, anchored from 1 (= 'Less effective') to 5 (= 'Highly effective'). These 3 items are measuring "the Effectiveness of Concurrent phase".

This Consequent phase refers to the outcomes of the negotiation (Paik \& Tung, 1999). They are generally considered as distributive (win-lose) or integrative (win-win). In the context of cross-border M\&A, the consequent phase is an agreement of a cross-border M\&A deal. The effectiveness of Consequent phase depends on whether an agreement is reached between the foreign target firm and UK acquiring firm. Based on an objective measure, we created a dummy variable for the Consequent phase where the cross border acquisitions assumed the value ' 1 ' if agreement of a cross-border M\&A deal is reached and ' 0 ' otherwise. This measure of consequent phase is used in the subsequent data analysis.

\section{The explanatory variables:}

\section{National cultural distance}

GLOBE practices scores were used to measure National cultural distance (House et al. 2004). This study used the GLOBE measures for the following reasons. 1) The GLOBE study used 
qualitative methods to assist the development of quantitative survey instruments. 2) The GLOBE study is not based solely on nations (for instance, French and English-speaking Canada is separated). 3) The data is collected in 951 organizations instead of just one.

Based on the nine dimensions of the GLOBE-practices scores, this study built an index of national culture differences following Morosini, Shane and Singh (1998). The index represents the aggregate national culture distance of the two acquisition parties:

$$
C D_{j}=\sqrt{\sum\left(I_{i j}-I_{i k}\right)^{2}}
$$

Where:

$C D_{j} \quad:$ The cultural differences for the $j$ th country

$I_{i j} \quad$ : GLOBE score for $i$ th cultural dimension and $j$ th country

$k \quad$ : Indicates UK.

Greater values on the cultural distance measures indicate greater differences or distance between the UK and the local firm's country with respect to the cultural dimension.

\section{Organizational culture differences}

Based on prior studies, Organizational cultural difference was measured using four items (Chatterjee et al., 1992; Datta, 1991). The respondents were asked to determine the extent to which the acquired firm differed from the acquiring firm in (1) General management style, (2) Values, beliefs and philosophy, (3) Reward and evaluation systems, (4) Approach to risk taking. Each item was measured on a Likert-type scale, anchored from 1 (= 'Very similar') to 5 (= 'Very different'). EFA produced one factor for the four measures of organizational culture differences, which explained a total of 70.69 percent of the observed variance. A composite measure of organizational culture difference was calculated by averaging the factor scores for the items that loaded on the single factor (Cronbach's $\alpha=0.89$ ). 


\section{Communication}

Building on Daft and Lengel's (1986) theory of media richness, several authors developed a measure to determine the extent to which organization members engage through different network ties in communication with varying degrees of richness (e.g., Whitfield, Lamont, and Sambamurthy, 1996). We adjusted this measure to comprise five items that asked the respondent to rate the extent to which organization members communicated with target firm boundaries through media such as use of first name, email, phone conversations, formal meetings, and socializing outside of work. All items used a five-point Likert-type scale ranging from 1 (= 'hardly ever') to 5 (= 'very frequently'). An attempt was made to identify a parsimonious set of variables to determine the underlying dimensions governing the full set of five measures of communication. Exploratory factor analysis (EFA) using varimax rotation was used to extract the underlying factors. The EFA produced one factor for the five measures of communication. The factor explained a total of 66.96 percent of the observed variance (with Cronbach's $\alpha=0.81$ ).

\section{Planned employee retention}

Respondents were asked to indicate the importance of retaining employees during the preacquisition stage (following Ranft and Lord, 2000), on a Likert-type scale anchored from 1 (= 'not important') to 5 (= 'extremely important') based on the employees' position within the acquired firm: (i) top management, (ii) middle management, (iii) research and development (iv) manufacturing and operations (v) marketing, sales and distribution, and (vi) finance, legal and other staff. EFA produced one factor for the six types of employees. Respondents were also asked to indicate the extent to which employees of the target firm was planned to retain on a Likert-type scale anchored from 1 (= 'no retention') and 5 (= 'full retention'). We 
calculated a composite measure of "planned employee retention" by multiplying the factor score on "importance" with the measures of "retention" and then taking the average of scores.

\section{Control Variables:}

Three control variables were included in the statistical model: industry relatedness between the UK acquiring firm and foreign target firm, relative size of the foreign target firm, and prior performance of target firm.

The relatedness of the acquiring firm and the acquired firm was coded as a binary variable depending on whether or not the acquirer and the acquired firms operated in the same industry as indicated by the respondent (Lubatkin, Merchant, and Srinivasan 1993). To control for potential effects of relatedness, the relatedness of the acquired firm and the acquirer was coded ' 1 'if 'related' and '0' if 'not related' acquisitions.

Relative size was operationalised as the ratio of the sales turnover of the acquired firm to that of the acquiring firm at the time of the acquisition (following Krishnan et al, 1997, and Schoenberg, 2004).

To measure prior performance of target firm, respondents were asked to indicate the profitability (return on capital employed) of the acquired firm relative to the acquiring firm at the time of acquisition on a scale ranging from $1=$ 'very poor' to $5=$ 'very good'. 


\section{FINDINGS}

The survey data were screened to check for outliers, out-of-range values, missing data. Descriptive statistics and correlations for each of the variables used in the analyses are presented in Table 3.

----Please insert Table 3 about here----

We analyzed the data using Partial Least Square (PLS) analysis. SmartPLS 2.0 (Ringle, Sven and Alexander, 2005) was used to carry out the PLS tests. PLS is a powerful multivariate analysis technique (Fornell and Bookstein, 1982). The primary goal of PLS, as opposed to covariance-based structural equation modelling, is to maximize the variance explained in latent and endogenous variables. PLS is widely used in analyzing data for the estimation of complex relationship between constructs in business and management (Gudergan et al. 2008). PLS-SEM is used in M\&A research (e.g. Cording, Christmann and King, 2008) and international marketing (e.g. Hair et al. 2012; Henseler, Ringle, and Sinkovics, 2009).

We checked the reliability and validity of the measures used in our model. Table 4 reports the Cronbach's Alpha, Composite reliability, and AVE (Average variance explained). The traditional criterion for internal consistency is Cronbach's Alpha which provides an estimate for the reliability based on the indicator inter-correlations. Cronbach's Alpha for all indicators are greater than 0.70. As Cronbach's Alpha tends to provide a major underestimation of the internal consistency reliability of latent variables in PLS path model, the 'composite reliability' is more appropriate measure of internal consistency (Henseler, Ringle and Sinkovics (2009, p.299). Using the measure suggested by Fornell and Larcker (1981), we found that all composite reliability values exceeded the minimum threshold of 
0.70 (Nunnally and Bernstein, 1994). Fornell and Larcker (1981) recommended using the Average Variance Extracted (AVE) as a criterion of convergent validity. An AVE value of at least 0.50 suggests adequate convergent validity, meaning that a latent variable is able to explain more than half of the variance of its indicators on average (Gotz, Liehr-Gobbers and Krafft, 2009). Table 4 indicates that the AVE values for latent variables are greater than 0.50 (except "national cultural distance x communication" which is about 0.48).

----Please insert Table 4 about here----

Table 4 also indicates the construct validity. An indicator for the construct validity is the Rsquared. The R-squared on antecedent phase, concurrent phase and consequent phase is $0.1376,0.5842$ and 0.1216 , respectively. This means that our model explains about $14 \%$ of the variance in antecedent phase, about $59 \%$ of the variance in the concurrent phase and about $12 \%$ variance in consequent phase.

To test the hypotheses, a structural model was built using the SmartPLS 2.0 program. The path coefficients are produced using a bootstrapping procedure. SmartPLS calculated the path coefficient estimates. Each path corresponds to one hypothesis. Table 5 shows the overview of path model.

----Please insert Table 5 about here----

Hypothesis 1, arguing that communication between the acquiring and target firm will positively influence the effectiveness of antecedent phase, is supported. The coefficient is positive $(\beta=0.3709)$, and the path is statistically significant $(\mathrm{p}<0.01)$. Thus, diverse 
communication methods and higher frequency have positive impact on the effectiveness of antecedent phase of a negotiation process.

PLS path model provides support for hypothesis 2 about the positive effect of communication on the effectiveness of concurrent phase. The coefficient is positive $(\beta=0.4212)$ and the path is statistically significant $(\mathrm{p}<0.01)$. Thus, the effectiveness of concurrent phase is positively influenced by the extent of communication between the acquiring and target firm.

Hypothesis 3 is supported: National cultural distance is negatively $(\beta=-0.1347)$ and significantly $(\mathrm{p}<0.10)$ related to the effectiveness of concurrent phase. Therefore, the greater the national cultural distance, the lower the effectiveness of concurrent phase of a negotiation process is.

Hypothesis 4 suggested that organizational cultural differences can negatively influence the effectiveness of concurrent phase. The coefficient is negative $(\beta=-0.1921)$ and the path is statistically significant $(\mathrm{p}<0.10)$. Accordingly, the higher the organisational cultural difference, the lower the effectiveness of concurrent phase of a negotiation process is.

PLS path model provides support for hypothesis 5 about the positive effect of planned employee retention on the effectiveness of concurrent phase. The coefficient is positive $(\beta=$ $0.2542)$ and the path is statistically significant $(\mathrm{p}<0.10)$. Thus, the effectiveness of concurrent phase is positively influenced by the planned employee retention of the target firm.

Hypothesis 6, arguing that national cultural distance negatively moderates the relationship between communication and concurrent phase of the negotiation process, is supported. The coefficient is negative $(\beta=-0.2534)$, and the path is statistically significant $(p<0.10)$. 
Consequently, the positive effect of communication is lowest when the national cultural distance between acquiring and target firm is very high.

Hypothesis 7 is not supported: the coefficient is negative $(\beta=-0.3012)$ but statistically insignificant $(\mathrm{p}>0.10)$. In addition, Hypothesis 8 is not supported. The coefficient is negative $(\beta=-0.1029)$ but statistically insignificant $(\mathrm{p}>0.10)$.

PLS path model provides support for hypothesis 9 about the positive effect of the effectiveness of concurrent phase on the effectiveness of consequent phase. The coefficient is positive $(\beta=0.2542)$ and the path is statistically significant $(\mathrm{p}<0.01)$. Thus, the effectiveness of consequent phase is positively influenced by the effectiveness of concurrent phase of the negotiation process.

With regards to control variables, relative size and prior performance of the target firm have no influence on the consequent phase of negotiation process. However, industry relatedness is positively influence the consequent phase of negotiation process $(\beta=0.2731 ; \mathrm{p}<0.01)$. The findings tend to indicate that industry relatedness between the acquiring and target firm is expected to have a positive impact on the M\&A agreement.

\section{DISCUSSION}

In the context of cross border acquisitions, scant research exists investigating the impact of communication, national cultural distance, organisational cultural differences, and planned employee retention on the various stages of negotiation process (e.g. antecedent, concurrent and consequent phases). Our paper contributes by examining the effect of communication on the effectiveness of antecedent and concurrent phase of the negotiation process. The findings provide strong support for the argument that frequent communication using diverse method 
can positively influences the effectiveness of antecedent phase of the negotiation process. Our finding is consistent with Valley et al. (1998), who suggested that medium choice of communication affects the negotiation process. While maintaining confidentially of negotiation details is important, relevant information sharing about the M\&A deal can prevent rumours from flourishing (Risberg, 1999). Clear and frequent communication involving key stakeholders can assist parties involved in the negotiation process in understanding and managing various expectations. Consequently, the likelihood of an effective negotiation process will be higher.

Our paper also contributes to the existing literature by examining the direct and moderating affect of national cultural distance and organizational cultural differences on the concurrent phase of the negotiation process in cross border acquisitions. We found that both national cultural distance and organizational cultural differences can have direct and negative impact on the effectiveness of concurrent phase of the negotiation process. Differences in national culture and diversity in philosophies, values and behaviour of the management team can lead to uncertainty amongst managers of target firm involved in M\&A deal (Buono and Bowditch, 1989), which may develop into feelings of anxiety and resentment (Cartwright and Cooper, 1992). These negative feeling in turn can result in conflicts between the acquiring firm and target firm (Sales and Mirvis, 1984), and reduced commitment towards cooperation (Weber et al, 1996). Consequently, the likelihood of organizational conflict is higher when organizations involved in M\&A deal have higher cultural dissimilarities (Sarala, 2010). Therefore, during the concurrent phase of the negotiation process, the chances of cooperation between the acquiring and target firm is low when parties negotiating have high national cultural distance and greater organizational cultural differences. Consequently, effectiveness of the concurrent phase of the negotiation process can be impaired in cross border acquisition. 
Apart from direct impact, national cultural distance and organizational cultural differences can moderate the relationship between communication and effectiveness of concurrent phase of the negotiation process in cross border acquisitions. We found that the positive impact of communication on the effectiveness of concurrent phase of the negotiation process is lower when acquiring and target firm have large national and organizational cultural dissimilarities. In the context of cross border acquisitions, national cultural distance and organizational cultural differences can lead to a diverse communication strategy, which may lead to different negotiation strategy and outcome (Liu \& Woywode, 2011). While "communication" has a significant impact on negotiation process, the finding tends to suggest that the extent of benefit arising from frequent communication could be limited when parties negotiating M\&A deal have large national cultural distance and greater organizational cultural differences. During the concurrent phase of negotiation process, acquiring firm should carefully communicate relevant and appropriate amount of information. Irrelevant and inappropriate amount of information sharing can impair negotiators' effectiveness (Wiltermuth \& Neale, 2011).

Another contribution of the present study is related with the impact of cultural differences on the effectiveness of negotiation process in cross border acquisitions. Weber et al. (1996) found that organizational cultural differences and national cultural differences were different construct, having different impacts on M\&A performance. Teerikangas and Very (2006) suggested discriminating national and organizational culture. Following Weber et al. (1996) and Teerikangas and Very (2006), we separately tested the impact of national cultural differences and organizational differences on the negotiation process.

The paper contributes by investigating the impact of planned employee retention on the concurrent phase of negotiation process. The findings provide strong support for the argument that planned employee retention positively influences the effectiveness of 
concurrent phase of negotiation process. Buchholtz and Ribben (1994) suggested that an employee retention plan may lower CEO resistant to takeover. Such a plan can encourage cooperation during the negotiation process. Moreover, Konstantopoulos et al. (2009) argued that human beliefs and professional attitudes such the fear of change and the security during the negotiations affect the result of M\&A. In this case, employee retention plan can be perceived positively by the firms involved in M\&A negotiation process. As a result, the likelihood of an effective negotiation process will be higher when acquiring firm plan to retain employees of the target firm.

We also found that an effective concurrent phase positively influence the consequent phase i.e. outcome of the negotiation. An ineffective concurrent phase may lead to the break-down of the negotiation or lead to disagreement between the acquiring firm and foreign target firm. Therefore, the effectiveness of concurrent phase positively influences the consequent phase i.e. the outcome of cross border M\&A negotiation.

\section{CONCLUSION AND RECOMMENDATIONS}

The paper provides an empirical examination of the impact of national cultural distance, organisational cultural differences, communication, and planned employee retention on effective negotiation process. While negotiation and culture have received attention in social psychology and organizational behaviour research, our current understanding of how and when national cultural distance and organisational cultural differences, communication and planned employee retention influence cross border M\&A negotiation is limited. Hence, an important contribution of the paper is the examination of national cultural distance and organisational cultural differences, communication and planned employee retention.

In addition, prior researchers have identified a number of factors influencing the negotiation process such as cultural differences and communication. These factors have not been 
considered in a single study, but have arisen from a number of studies that have examined different factors. Our paper is novel in that we consider all the identified factors simultaneously and examine their impact on different phases of negotiation process (e.g. antecedent, concurrent and consequent phase).

The finding tends to indicate that communication between the acquiring firm and target firm directly influence the effectiveness of antecedent phase of negotiation process. In addition, the findings indicate that the effectiveness of concurrent phase can directly be influenced by communication, national cultural distance, organizational cultural differences, and planned employee retention. Moreover, we found that national cultural distance negatively moderates the relationship between communication and the effectiveness of concurrent phase as such that the positive effect of communication is lowest when the national cultural distance between the acquiring and target firm is higher. Finally, we found that the effectiveness of concurrent phase positively influence the effectiveness of consequent phase.

The study has implication for managers involved cross border acquisitions. Firstly, we developed and tested a conceptual framework of negotiation process in order to provide a framework to analyze the key components of the negotiation stage of the cross border M\&A process. As such, the presented framework is essential to practitioners. Practitioners gain insight into the significance of considering multiple factors during the M\&A negotiation stage, which permits the acquiring and target firms to accomplish an agreement that better positions the combined firm to create value following the deal. Also, understanding vital components of the negotiation stage and their effects can assist practitioners, especially those planning to engage in multiple deals, to focus efforts on certain negotiation practices while becoming more thriving in M\&A negotiations. 
In addition, the contribution of this study lies in providing new insights on negotiationassociated factors for incumbent executives in order to enable them to better plan and implement cross-border M\&A deals. We found that national cultural distance can have negative impact on the concurrent phase of negotiation process. Therefore, we recommend that managers involved in M\&A negotiation process assess the national cultural distance and attempt to understand the existing differences between acquiring and target firm. Such assessment and appreciation of national cultural distance can assist acquiring firms to formulate more effective negotiation strategy.

Finally, we also found that national cultural distance moderates the relationship between communication and effectiveness of concurrent phase as such that the positive effect of communication on concurrent phase is lower when national cultural distance is higher. We suggest that managers involved M\&A negotiation process attempt to anticipate the likely impact of any information on target firm before actually sharing the information. Such anticipation is even more important when parties involved in M\&A have large national cultural distance. Our findings also suggest that managers involved in M\&A should communicate relevant and optimal information. Example of relevant information is the plan to retain employees of the target firm. Information about the employee retention plan should be communicated with the target firm which can facilitate effective negotiation process. 


\section{References}

Adair, W. L., \& Brett, J. M. 2005. The negotiation dance: Time, culture, and behavioral sequences in negotiation. Organization Science, 16(1): 33-51.

Adair, W. L., Okumura, T., \& Brett, J. M. 2001. Negotiation behavior when cultures collide: The United States and Japan. Journal of Applied Psychology, 86(3): 371.

Allatta, J. T., \& Singh, H. 2011. Evolving communication patterns in response to an acquisition event. Strategic Management Journal, 32:1099-1118.

Almor, T., Tarba, S. Y., \& Benjamini, H. 2009. Unmasking integration challenges: The Case of Biogal's Acquisition by Teva Pharmaceutical Industries. International Studies of Management and Organization, 39(3): 32-52.

Angwin, D. 2001. Mergers and acquisitions across European borders: National perspectives on preacquisition due diligence and the use of professional advisers. Journal of World Business, 36(1): 32-57.

Bazerman, M. H., Curhan, J. R., Moore, D. A., \& Valley, K. L. 2000. Negotiation. Annual Review of Psychology, 51(1): 279-314.

Brett, J. F., Northcraft, G. B., \& Pinkley, R. L. 1999. Stairways to heaven: An interlocking self-regulation model of negotiation. Academy of Management Review, 24(3): 435451.

Brett, J. M., \& Okumura, T. 1998. Inter-and intracultural negotiation: US and Japanese negotiators. Academy of Management Journal, 495-510.

Brouthers, K. D., \& Bamossy, G. J. 1997. The role of key stakeholders in international joint venture negotiations: Case studies from Eastern Europe. Journal of International Business Studies, 285-308.

Buchholtz, A. K., \& Ribbens, B. A. 1994. Role of chief executive officers in takeover resistance: Effects of CEO incentives and individual characteristics. Academy of Management Journal, 37(3): 554-579.

Cartwright, S., \& Cooper, C. L. 1993. The psychological impact of merger and acquisition on the individual: A study of building society managers. Human Relations, 46(3): 327.

Cartwright, S., \& Schoenberg, R. 2006. Thirty years of mergers and acquisitions research: Recent advances and future opportunities. British Journal of Management, 17: S1S5.

Chesbrough, H. W., \& Teece, D. J. 2002. Organizing for innovation: When is virtual virtuous? Harvard Business Review, 80(1): 127-135.

de Beaufort, V., \& Lempereur, A. P. 2003. Negotiating mergers and acquisitions in the European Union. In P. Ghauri, \& J. Usunier (Eds.), International Business Negotiation: 291-324. Oxford, UK: Pergamon.

DeRue, D. S., Conlon, D. E., Moon, H., \& Willaby, H. W. 2009. When is straightforwardness a liability in negotiations? The role of integrative potential and structural power. Journal of Applied Psychology, 94(4): 1032.

Drolet, A. L., \& Morris, M. W. 2000. Rapport in conflict resolution: Accounting for how face-to-face contact fosters mutual cooperation in mixed-motive conflicts. Journal of Experimental Social Psychology, 36(1): 26-50.

Fang, T., Fridh, C., \& Schultzberg, S. 2004. Why did the Telia-Telenor merger fail. International Business Review, 13(5): 573-594.

Gelfand, M., \& Dyer, N. 2000. A cultural perspective on negotiation: Progress, pitfalls, and prospects. Applied Psychology, 49(1): 62-99.

Gelfand, M. J., \& Brett, J. M. 2004. The Handbook of Negotiation and Culture. Stanford, California: Stanford University Press. 
Gelfand, M. J., \& Christakopoulou, S. 1999. Culture and negotiator cognition: Judgment accuracy and negotiation processes in individualistic and collectivistic cultures. Organizational Behavior and Human Decision Processes, 79(3): 248-269.

Gelfand, M. J., Higgins, M., Nishii, L. H., Raver, J. L., Dominguez, A., Murakami, F., Yamaguchi, S., \& Toyama, M. 2002. Culture and egocentric perceptions of fairness in conflict and negotiation. Journal of Applied Psychology, 87(5): 833.

Gelfand, M. J., Major, V. S., Raver, J. L., Nishii, L. H., \& O'Brien, K. 2006. Negotiating relationally: The dynamics of the relational self in negotiations. The Academy of Management Review, 31(2): 427-451.

Gelfand, M. J., Raver, J. L., Nishii, L., Leslie, L. M., Lun, J., Lim, B. C., Duan, L., Almaliach, A., Ang, S., \& Arnadottir, J. 2011. Differences between tight and loose cultures: A 33-nation study. Science, 332(6033): 1100.

Gelfand, M. J., \& Realo, A. 1999. Individualism-collectivism and accountability in intergroup negotiations. Journal of Applied Psychology, 84(5): 721.

George, J. M., Jones, G. R., \& Gonzalez, J. A. 1998. The role of affect in cross-cultural negotiations. Journal of International Business Studies, 749-772.

Ghauri, P., \& Fang, T. 2001. Negotiating with the Chinese: A socio-cultural analysis. Journal of World Business, 36(3): 303-325.

Ghauri, P. N. 2003. A framework for international business negotiations. In G. J. C. Usunier (Ed.), International Business Negotiations: 3-22. Kidlington, Oxford: Pergamon.

Ghauri, P. N., \& Usunier, J.-C. 2003. International Business Negotiations. Kidlington, Oxford: Pergamon.

Gomes, E., Weber, Y., Brown, C., \& Tarba, S. Y. 2011a. Mergers, Acquisitions and Strategic Alliances: Understanding the Process. Basingstoke, UK: Palgrave Macmillan.

Graham, J. L. 1985a. Cross-cultural marketing negotiations: A laboratory experiment. Marketing Science, 130-146.

Graham, J. L. 1985b. The influence of culture on the process of business negotiations: An exploratory study. Journal of International Business Studies, 81-96.

Graham, J. L. 1993. The Japanese negotiation style: Characteristics of a distinct approach. Negotiation Journal, 9(2): 123-140.

Graham, J. L., \& Lam, N. M. 2003. The Chinese negotiation. Harvard Business Review, 81(10): 82-91.

Graham, J. L., Mintu, A. T., \& Rodgers, W. 1994. Explorations of negotiation behaviors in ten foreign cultures using a model developed in the United States. Management Science, 72-95.

Greenhalgh, L., Neslin, S. A., \& Gilkey, R. W. 1985. The effects of negotiator preferences, situational power, and negotiator personality on outcomes of business negotiations. Academy of Management Journal, 28(1): 9-33.

Hambrick, D. C., \& Cannella Jr, A. A. 1993. Relative standing: A framework for understanding departures of acquired executives. Academy of Management Journal, 36(4): 733-762.

Kirkman, B. L., Lowe, K. B., \& Gibson, C. B. 2006. A quarter century of culture's consequences: A review of empirical research incorporating Hofstede's cultural values framework. Journal of International Business Studies, 37(3): 285-320.

Konstantopoulos, N., Sakas, D., \& Triantafyllopoulos, Y. 2009. Lessons from a case study for Greek banking M\&A negotiations. Management Decision, 47(8): 1300-1312.

Kumar, R. 2004. Culture and emotions in intercultural negotiations: An overview. In M. J. Gelfand, \& J. M. Brett (Eds.), The Handbook of Negotiation and Culture: 95-113. Stanford, California: Stanford University Press. 
La Piana, D., \& Hayes, M. 2005. M\&A in the nonprofit sector: managing merger negotiations and integration. Strategy \& Leadership, 33(2): 11-16.

Larsson, R., \& Finkelstein, S. 1999. Integrating strategic, organizational, and human resource perspectives on mergers and acquisitions: A case survey of synergy realization. Organization Science, 10(1): 1-26.

Larsson, R., \& Lubatkin, M. 2001. Achieving acculturation in mergers and acquisitions: An international case survey. Human Relations, 54(12): 1573-1607.

Lee, K., Yang, G., \& Graham, J. L. 2006. Tension and trust in international business negotiations: American executives negotiating with Chinese executives. Journal of International Business Studies, 37(5): 623-641.

Leung, K. 1997. Negotiation and reward allocations across cultures. In P. C. Earley, \& M. Erez (Eds.), New Perspectives on International Industrial/Organizational Psychology: 640-675. San Francisco: Jossey-Bass.

Lewicki, R. J., Weiss, S. E., \& Lewin, D. 1992. Models of conflict, negotiation and third party intervention: A review and synthesis. Journal of Organizational Behavior, 13(3): 209-252.

Lewis, S. A., \& Fry, W. R. 1977. Effects of visual access and orientation on the discovery of integrative bargaining alternatives. Organizational Behavior and Human Performance, 20(1): 75-92.

Liu, L. A., Chua, C. H., \& Stahl, G. K. 2010. Quality of communication experience: Definition, measurement, and implications for intercultural negotiations. Journal of Applied Psychology, 95(3): 469.

Liu, Y., \& Woywode, M. 2011. Chinese M\&A in Germany. In I. Alon, M. Fetscherin, \& P. Gugler (Eds.), Chinese International Investments. UK/Hampshire: Palgrave Macmillan

Luo, Y. 1999. Toward a conceptual framework of international joint venture negotiations. Journal of International Management, 5(2): 141-165.

Luo, Y., \& Shenkar, O. 2002. An empirical inquiry of negotiation effects in cross-cultural joint ventures. Journal of International Management, 8(2): 141-162.

Meyer, C. B., \& Altenborg, E. 2008. Incompatible strategies in international mergers: the failed merger between Telia and Telenor. Journal of International Business Studies, 39(3): 508-525.

Paik, Y., \& Tung, R. L. 1999. Negotiating with East Asians: How to attain" win-win" outcomes. Management International Review, 39(2): 103-122.

Ranft, A. L., \& Lord, M. D. 2002. Acquiring new technologies and capabilities: A grounded model of acquisition implementation. Organization Science, 420-441.

Rao, A., \& Schmidt, S. M. 1998. A behavioral perspective on negotiating international alliances. Journal of International Business Studies, 665-693.

Riad, S., Vaara, E., \& Zhang, N. 2012. The Intertextual production of international relations in mergers and acquisitions. Organization Studies, 33(1): 121-148.

Saorín-Iborra, M. C. 2008. Time pressure in acquisition negotiations: Its determinants and effects on parties' negotiation behaviour choice. International Business Review, 17(3): 285-309.

Saorín-lborra, M. C. 2006. A review of negotiation outcome: A proposal on delimitation and subsequent assessment in joint venture negotiations. Canadian Journal of Administrative Sciences/Revue Canadienne des Sciences de l'Administration, 23(3): 237-252.

Sarala, R. M. 2010. The impact of cultural differences and acculturation factors on postacquisition conflict. Scandinavian Journal of Management, 26(1): 38-56. 
Sarala, R. M., \& Vaara, E. 2010. Cultural differences, convergence, and crossvergence as explanations of knowledge transfer in international acquisitions. Journal of International Business Studies, 41(8): 1365-1390.

Schweiger, D. M., \& Denisi, A. S. 1991. Communication with employees following a merger - A longitudinal field experiment. Academy of Management Journal, 34(1): 110-135.

Sebenius, J. K. 1998. Negotiating cross-border acquisitions. MIT Sloan Management Review, 39(2): 27-41.

Sebenius, J. K. 2002a. Caveats for cross-border negotiators. Negotiation Journal, 18(2): 121133.

Sebenius, J. K. 2002b. The hidden challenge of cross-border negotiations. Harvard Business Review, 80(3): 76-85.

Sebenius, J. K., \& Qian, C. J. 2008. Cultural notes on Chinese negotiating behavior. Harvard Business School Working Paper No. 09-076.

Shrivastava, P. 1986. Smoothing postmerger integration. Journal of Business Strategy, 7(1): 65-76.

Sinkovics, R. R., Zagelmeyer, S., \& Kusstatscher, V. 2011. Between merger and syndrome: The intermediary role of emotions in four cross-border M\&As. International Business Review, 20(1): 27-47.

Stahl, G. K., \& Voigt, A. 2008. Do cultural differences matter in mergers and acquisitions? A tentative model and examination. Organization Science, 19(1): 160-176.

Tarba, S. Y., Almor, T., \& Benyamini, H. 2011. A comparative anatomy of two cross-border acquisitions by Teva pharmaceutical industries. In C. L. Cooper, \& S. Finkelstein (Eds.), Advances in Mergers and Acquisitions, Vol. 10: 75-102.: Emerald Group Publishing Limited.

Teerikangas, S. 2012. Dynamics of acquired firm pre-acquisition employee reactions. Journal of Management, 38(2): 599-639.

Thompson, L. L., Wang, J., \& Gunia, B. C. 2010. Negotiation. Annual review of psychology, 61: 491-515.

Tinsley, C. H. 2001. How negotiators get to yes: Predicting the constellation of strategies used across cultures to negotiate conflict. Journal of Applied Psychology, 86(4): 583.

Tinsley, C. H., Curhan, J. J., \& Kwak, R. S. 1999. Adopting a dual lens approach for examining the dilemma of differences in international business negotiations. International Negotiation, 4(1): 5-22.

Tse, D. K., Francis, J., \& Walls, J. 1994. Cultural differences in conducting intra-and intercultural negotiations: A Sino-Canadian comparison. Journal of International Business Studies, 537-555.

Valley, K. L., Moag, J., \& Bazerman, M. H. 1998. A matter of trust': Effects of communication on the efficiency and distribution of outcomes. Journal of Economic Behavior \& Organization, 34(2): 211-238.

Wade-Benzoni, K. A., Hoffman, A. J., Thompson, L. L., Moore, D. A., Gillespie, J. J., \& Bazerman, M. H. 2002. Barriers to resolution in ideologically based negotiations: The role of values and institutions. Academy of Management Review, 27(1): 41-57.

Walsh, J. P. 1989. Doing a deal: Merger and acquisition negotiations and their impact upon target company top management turnover. Strategic Management Journal, 10(4): 307-322.

Weber, Y. 1996. Corporate cultural fit and performance in mergers and acquisitions. Human Relations, 49(9): 1181-1202.

Weber, Y., Rachman-Moore, D., \& Tarba, S. Y. 2011. HR practices during post-merger conflict and merger performance. International Journal of Cross-Cultural Management, 12(1): 73-99. 
Weber, Y., Shenkar, O., \& Raveh, A. 1996. National and corporate cultural fit in mergers/acquisitions: An exploratory study. Management Science, 42(8): 1215-1227.

Weber, Y., \& Tarba, S. Y. 2010. Human resource practices and performance of mergers and acquisitions in Israel. Human Resource Management review, 20(3): 203-211.

Weber, Y., Tarba, S. Y., \& Bachar, Z. R. 2011. Mergers and acquisitions performance paradox: the mediating role of integration approach. European Journal of International Management, 5(4): 373-393.

Weber, Y., Tarba, S. Y. and Öberg, C. (2014). A Comprehensive Guide to Mergers and Acquisitions: Managing The Critical Success Factors Across Every Stage of The M\&A Process. New York - London: Pearson and Financial Times Press.

Weber, Y., Tarba, S. Y., \& Reichel, A. 2011. A model of the influence of culture on integration approaches and international mergers and acquisitions performance. International Studies of Management and Organization, 41(3): 9-24.

Weber, Y., Teerikangas, S., Rouzies, A., \& Tarba, S. Y. 2011. Cross-cultural management in mergers and acquisitions-Editorial. European Journal of International Management, 5(4): 319-326.

Weingart, L. R., \& Olekalns, M. 2004. Communication processes in negotiation: Frequencies, sequences, and phases. In M. J. Gelfand, \& J. M. Brett (Eds.), The Handbook of Negotiation and Culture: 143-157. Stanford, California: Stanford University Press.

Weiss, S. E. 1993. Analysis of complex negotiations in international business: The RBC perspective. Organization Science, 269-300.

Weiss, S. E. 2006. International business negotiation in a globalizing world: Reflections on the contributions and future of a (sub) field. International Negotiation, 11(2): 287316.

Wiltermuth, S. S., \& Neale, M. A. 2011. Too much information: The perils of nondiagnostic information in negotiations. Journal of Applied Psychology, 96(1): 192. 
Figure 1 - A conceptual framework of negotiation process in cross border M\&A

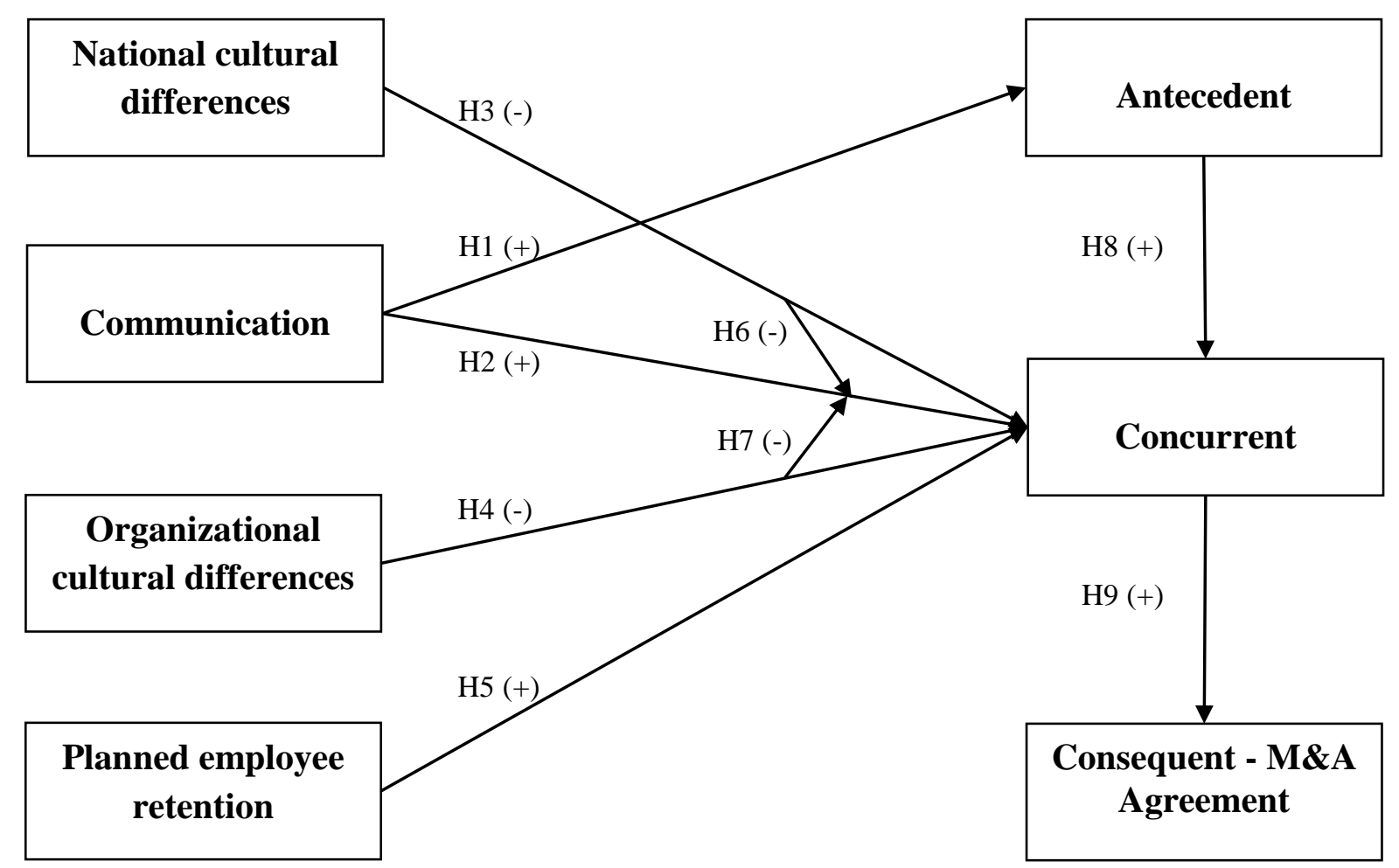


Table 1: Comparisons of 2000 and 2004 acquisitions

\begin{tabular}{lccccc}
\hline & \multicolumn{2}{c}{$\mathbf{2 0 0 0}$} & \multicolumn{2}{c}{$\mathbf{2 0 0 4}$} & T-value \\
$(\mathbf{n = \mathbf { 2 5 } )}$ & Mean & S.D. & Mean & S.D. & \\
\hline National Cultural distance & 1.560 & 0.520 & 1.435 & 0.474 & -0.817 \\
\hline Organisational Cultural differences & -0.237 & 1.090 & 0.133 & 0.980 & 1.164 \\
\hline Communication & -0.03 & 1.046 & -0.06 & 1.151 & -0.083 \\
\hline Planned Employee Retention & 3.333 & 0.996 & 3.266 & 1.042 & -0.219 \\
\hline Concurrent Phase & 3.687 & 1.144 & 3.771 & 1.131 & 0.244 \\
\hline
\end{tabular}


Table 2: Comparisons of early and late respondents

\begin{tabular}{|c|c|c|c|c|c|}
\hline & \multicolumn{2}{|c|}{$\begin{array}{l}\text { Early Respondents } \\
\qquad(\mathrm{n}=\mathbf{3 9})\end{array}$} & \multicolumn{2}{|c|}{$\begin{array}{l}\text { Late Respondents } \\
\qquad(\mathrm{n}=\mathbf{2 6})\end{array}$} & \multirow[t]{2}{*}{ T-test } \\
\hline & Mean & S.D. & Mean & S.D. & \\
\hline National Cultural distance & 1.489 & 0.496 & 1.315 & 0.368 & 1.378 \\
\hline Organisational Cultural differences & 0.030 & 0.941 & -0.133 & 1.266 & 0.423 \\
\hline Communication & 0.05 & 0.971 & -0.21 & 1.139 & 0.738 \\
\hline Planned Employee Retention & 3.314 & 0.884 & 3.055 & 1.187 & 0.712 \\
\hline Concurrent Phase & 3.767 & 0.979 & 3.638 & 1.313 & 0.319 \\
\hline
\end{tabular}


Table 3: Descriptive statistics and Pearson's correlations

\begin{tabular}{|c|c|c|c|c|c|c|c|c|c|c|c|c|c|c|}
\hline & Mean & S.D. & 1 & 2 & 3 & 4 & 5 & 6 & 7 & 8 & 9 & 10 & 11 & 12 \\
\hline 1. Agreement & $1 / 0$ & $\mathrm{n} / \mathrm{a}$ & 1.00 & & & & & & & & & & & \\
\hline 2. Antecedent Phase & 2.458 & 0.678 & 0.113 & 1.00 & & & & & & & & & & \\
\hline 3. Communication & 3.820 & 0.890 & -0.054 & $0.370^{*}$ & 1.00 & & & & & & & & & \\
\hline 4. Concurrent Phase & 3.743 & 1.038 & -0.178 & 0.105 & $0.559 * *$ & 1.00 & & & & & & & & \\
\hline 5. Employee retention & 3.317 & 0.854 & 0.058 & $0.272 *$ & $0.599 * *$ & $0.556 * *$ & 1.00 & & & & & & & \\
\hline 6. National Cultural Differences & 1.457 & 0.477 & $0.271 *$ & 0.134 & 0.172 & -0.014 & 0.104 & 1.00 & & & & & & \\
\hline $\begin{array}{l}\text { 7. Communication X National } \\
\text { Cultural Differences }\end{array}$ & 0.0536 & 1.357 & -0.049 & $-0.358^{*}$ & $-0.493 * *$ & -0.176 & $-0.445^{* *}$ & 0.101 & 1.00 & & & & & \\
\hline $\begin{array}{l}\text { 8. Organizational cultural } \\
\text { differences }\end{array}$ & 2.910 & 0.800 & -0.201 & 0.066 & $0.259^{*}$ & $0.500 * *$ & $0.382 *$ & -0.104 & -0.168 & 1.00 & & & & \\
\hline $\begin{array}{l}\text { 9. Communication X Organizational } \\
\text { cultural differences }\end{array}$ & -0.012 & 0.767 & -0.040 & $-0.261^{*}$ & $-0.406 * *$ & $-0.546 * *$ & $-0.436^{* *}$ & -0.096 & $0.331 *$ & $-0.454 * *$ & 1.00 & & & \\
\hline 10. Relatedness & $1 / 0$ & $\mathrm{n} / \mathrm{a}$ & 0.179 & $0.245^{*}$ & $0.297 *$ & $0.397 *$ & $0.399 *$ & 0.027 & $-0.299 *$ & 0.118 & $-0.331 *$ & 1.00 & & \\
\hline 11.Size & 2.458 & 1.077 & 0.060 & $0.418 * *$ & $0.402 * *$ & 0.188 & $0.503 * *$ & 0.015 & $-0.319 *$ & 0.185 & $-0.350 *$ & 0.228 & 1.00 & \\
\hline 12. past performance & 3.25 & 1.160 & -0.074 & 0.051 & 0.017 & -0.185 & 0.122 & 0.080 & $-0.283 *$ & 0.095 & 0.063 & -0.123 & $0.249 *$ & 1.00 \\
\hline
\end{tabular}

Note: $\mathrm{N}=65 ;$ S.D. $=$ Standard Deviation; $* * \mathrm{p}<0.01,{ }^{*} \mathrm{p}<0.05 ;$ Two-tailed test 
Table 4: Overview of path model

\begin{tabular}{|l|l|l|l|l|}
\hline & R-Square & AVE & $\begin{array}{l}\text { Composite } \\
\text { Reliability }\end{array}$ & $\begin{array}{l}\text { Cronbachs } \\
\text { Alpha }\end{array}$ \\
\hline Communication & & 0.5977 & 0.9216 & 0.9013 \\
\hline Employee retention & & 1.0000 & 1.0000 & 1.0000 \\
\hline National Cultural Differences & & 1.0000 & 1.0000 & 1.0000 \\
\hline Organizational cultural differences & & 0.5687 & 0.8401 & 0.7487 \\
\hline Antecedent Phase & 0.1376 & 0.8027 & 0.8905 & 0.7564 \\
\hline Concurrent Phase & 0.5842 & 0.7054 & 0.9052 & 0.8607 \\
\hline Agreement & 0.1216 & 1.0000 & 1.0000 & 1.0000 \\
\hline Communication X National Cultural Differences & & 0.4726 & 0.8664 & 0.8190 \\
\hline Communication X Organizational cultural differences & & 0.5792 & 0.9775 & 0.9768 \\
\hline Relatedness & & 1.0000 & 1.0000 & 1.0000 \\
\hline Size & & 1.0000 & 1.0000 & 1.0000 \\
\hline
\end{tabular}


Table 5: Partial Least Square (PLS) Path model

\begin{tabular}{|c|c|c|c|c|c|c|}
\hline Path & Coefficient & $\begin{array}{l}\text { Standard } \\
\text { deviation }\end{array}$ & $\begin{array}{c}\text { Standard } \\
\text { Error }\end{array}$ & T-statistics & p-value & Hypothesis \\
\hline Communication $\rightarrow$ Antecedent & 0.3709 & 0.0966 & 0.0966 & $3.8409 * * *$ & 0.000 & Supported \\
\hline Communication $\rightarrow$ Concurrent & 0.4212 & 0.1581 & 0.1581 & $2.6643 * * *$ & 0.009 & Supported \\
\hline National cultural differences $\rightarrow$ Concurrent & -0.1347 & 0.0772 & 0.0772 & $1.7446^{*}$ & 0.085 & Supported \\
\hline Organizational cultural differences $\rightarrow$ Concurrent & -0.1921 & 0.0997 & 0.0997 & $1.9272 *$ & 0.058 & Supported \\
\hline Planned Employee retention $\rightarrow$ Concurrent & 0.2542 & 0.1404 & 0.1404 & $1.8103^{*}$ & 0.074 & Supported \\
\hline Communication X National cultural differences $\rightarrow$ Concurrent & -0.2534 & 0.1479 & 0.1479 & $1.7131 *$ & 0.091 & Supported \\
\hline Communication X Organizational cultural differences $\rightarrow$ Concurrent & -0.3012 & 0.2934 & 0.2934 & 1.0266 & 0.308 & No support \\
\hline Antecedent $\rightarrow$ Concurrent & -0.1029 & 0.0804 & 0.0804 & 1.2804 & 0.205 & No support \\
\hline Concurrent $\rightarrow$ M\&A agreement & 0.3263 & 0.0872 & 0.0872 & $3.7420 * * *$ & 0.000 & Supported \\
\hline Industry Relatedness $\rightarrow$ M\&A agreement & 0.2731 & 0.0876 & 0.0876 & $3.1168 * * *$ & 0.002 & $\mathrm{n} / \mathrm{a}$ \\
\hline Relative size $\rightarrow$ M\&A agreement & 0.0900 & 0.1040 & 0.1040 & 0.8649 & 0.390 & $\mathrm{n} / \mathrm{a}$ \\
\hline Prior performance of target firm $\rightarrow$ M\&A agreement & -0.1236 & 0.1114 & 0.1114 & 1.1086 & 0.271 & $\mathrm{n} / \mathrm{a}$ \\
\hline
\end{tabular}

Note: $\mathrm{N}=65 ; \mathrm{p}$-values for 2 -tail test; $* * * \mathrm{p}<0.01, * * \mathrm{p}<0.05, * \mathrm{p}<0.10$ 